\title{
Article \\ Hydrophobic Anti-Reflective Coating of Plasma-Enhanced Chemical Vapor Deposited Diamond-Like Carbon Thin Films with Various Thicknesses for Dye-Sensitized Solar Cells ${ }^{\dagger}$
}

\author{
Jae-Sil Song ${ }^{1, \ddagger}$, Yong Seob Park ${ }^{2, \ddagger}$ and Nam-Hoon Kim ${ }^{1, *(\mathbb{D})}$ \\ 1 Department of Electrical Engineering, Chosun University, Gwangju 61452, Korea; songjeasil@korail.com \\ 2 Department of Electronics, Chosun College of Science \& Technology, Gwangju 61453, Korea; \\ yongspark@cst.ac.kr \\ * Correspondence: nhkim@chosun.ac.kr; Tel./Fax: +82-62-230-7028 \\ + A preliminary version of this work is part of J.-S. Song's Ph.D. dissertation. \\ $\ddagger \quad$ These authors contributed equally to this work.
}

check for updates

Citation: Song, J.-S.; Park, Y.S.; Kim, N.-H. Hydrophobic Anti-Reflective Coating of Plasma-Enhanced Chemical Vapor Deposited Diamond-Like Carbon Thin Films with Various Thicknesses for Dye-Sensitized Solar Cells . Appl. Sci. 2021, 11, 358. https://doi.org/ 10.3390/app11010358

Received: 7 December 2020 Accepted: 24 December 2020 Published: 1 January 2021

Publisher's Note: MDPI stays neutral with regard to jurisdictional clai$\mathrm{ms}$ in published maps and institutional affiliations.

Copyright: (C) 2021 by the authors. Licensee MDPI, Basel, Switzerland. This article is an open access article distributed under the terms and conditions of the Creative Commons Attribution (CC BY) license (https:// creativecommons.org/licenses/by/ $4.0 /)$.

\begin{abstract}
Diamond-like carbon (DLC) thin films, prepared by a radio frequency plasma-enhanced chemical vapor deposition (PECVD) system, were investigated for application as an anti-reflective coating (ARC) for dye-sensitized solar cells (DSSCs) with a change in film thickness. The strength of the Raman spectrum, G-peak position, and $\mathrm{I}_{D} / \mathrm{I}_{G}$ ratio, related to $s p^{3}$ bonds in the DLC thin films, is directly attributed to some tribological properties including surface roughness, hardness, elastic modulus, friction coefficient, and contact angle. Some optical properties, such as transmittance, refractive index, and absorption coefficient, were examined after changing the thickness of DLC thin films. The optimal short-circuit current density $\left(J_{s c}\right)$, open-circuit voltage $\left(V_{o c}\right)$, and fill factor (FF) values were obtained for the significantly improved conversion efficiency (CE) from $4.92 \%$ to $5.35 \%$ in the $60 \mathrm{~nm}$ thick PECVD DLC ARC for DSSCs with hard and hydrophobic surfaces.
\end{abstract}

Keywords: diamond-like carbon (DLC); anti-reflective coating (ARC); dye-sensitized solar cells (DSSCs); plasma-enhanced chemical vapor deposition (PECVD)

\section{Introduction}

Diamond-like carbon (DLC) has been extensively studied for decades owing to its excellent properties, such as very high hardness, low friction coefficient, chemical inactivity, wear resistance, optical transparency, and biocompatibility [1]. The physical and chemical properties of DLC thin films are in a quasi-stabilized form as their characteristics can be effectively controlled under synthesis conditions, which make them useful in a wide range of applications [2]. Recent studies have further expanded the application of DLC thin films by improving biocompatibility, lubrication, stability, and cell adhesion [3-6]. They have been effectively employed for surface modification, structural bonding $[7,8]$, surface roughing [9,10], hydrophilic/hydrophobic control [11,12], and doping of suitable elements/plasma treating [4-6,13]. To improve the efficiency and stability of solar cells, various studies have been conducted on the cleaning and texturing of substrates, enrichment, surface protection, and anti-reflection coatings [14,15]. While DLC thin films are applied as anti-reflective coatings (ARCs) of various solar cells based on c-Si and GaAs, dye-sensitized solar cells (DSSCs) are also expected to be useful for addressing the low energy conversion efficiency (CE) and lack of long-term stability by using the DLC ARC. In this study, a radio frequency $(\mathrm{RF})$ plasma-enhanced chemical vapor deposition (PECVD) system was employed to form DLC thin films as the ARC. DLC thin films were synthesized with various thicknesses at low temperature because the use of ARC in solar cells generally reduces the permeability of incident light into solar cells, and the refractive index of the ARC must be reduced to increase the transmittance. To address these problems, it is necessary to identify 
optimal conditions for developing DLC ARCs in which the transmittance and refractive index are acceptable at the appropriate thicknesses. The tribological, optical, and structural characteristics of the DLC thin films were also analyzed at different thicknesses to improve the energy CE and long-term stability of DSSCs.

\section{Experimental Details}

The DLC thin film was deposited using a $13.56 \mathrm{MHz}$ RF-PECVD system on $2 \mathrm{~cm} \times 2 \mathrm{~cm}$ glass and silicon substrates. To decontaminate the substrates surfaces before deposition, the substrate was cleaned with ultra-sonication, acetone, methanol, and deionized water (DIW). After cleaning, the native oxide film on the substrate was removed using a hydrogen fluoride (HF) solution. The substrates were dried with $\mathrm{N}_{2}$ gas and then mounted on the holder in PECVD. To improve adhesion between the substrate and DLC thin film, pretreatment was performed in the generated plasma by infusing $\mathrm{H}_{2}$ gas of $100 \mathrm{sccm}$ at an RF power of $140 \mathrm{~W}$ for $2 \mathrm{~min}$. The reaction gas was injected with a mixture of methane $\left(\mathrm{CH}_{4}\right)$ of $25 \mathrm{sccm}$ and $\mathrm{H}_{2}$ of $100 \mathrm{sccm}$ in a fixed condition; a base pressure of $2 \times 10^{-3}$ Torr, process pressure of 1 Torr, and RF power for plasma of $120 \mathrm{~W}$ at room temperature. The thickness of the DLC thin films was adjusted from 20 to $100 \mathrm{~nm}$ with a change in the deposition time.

Structural properties of the DLC thin films were analyzed using Raman spectroscopy (Jobin Yvon, LabRamHr, excitation wavelength of $514 \mathrm{~nm}$ ) [16], and surface characteristics were observed using field effect scanning electron microscope (FESEM, Hitachi, Tokyo, Japan, S-4700) and atomic force microscopy (AFM, Park Systems, Suwon, Korea, XE-200). Tribological characteristics including hardness and elastic modulus of the DLC thin films were examined by using a nanoindenter (MTS Systems Corp., Eden Prairie, MN, USA, Nanoindenter II) and nano scratch tester (Anton Paar GmbH, Graz, Austria, NST ${ }^{3}$ ). Optical properties, such as transmittance, refractive index, reflection, and absorption coefficient of DLC thin films were measured using an ultraviolet-visible spectrometer (SCINCO Co. Ltd., Seoul, Korea, S-2100) and spectroscopic ellipsometry (Horiba, Kyoto, Japan, UVISEL2).

The working electrode in a DSSC was fabricated by the doctor blade coating method using a slurry with $\mathrm{TiO}_{2}$ nanoparticles (13 nm, Solarnix SA, Aubonne, Switzerland) on fluorine-doped tin oxide (FTO, Solarnix SA, Aubonne, Switzerland, $8 \Omega$ /sq, 130-nm thickness, $1.5 \mathrm{~cm} \times 2 \mathrm{~cm}$ )/glass before it was sintered at $550{ }^{\circ} \mathrm{C}$ for $60 \mathrm{~min}$ in an active area of $0.25 \mathrm{~cm}^{2}$ to form $\mathrm{TiO}_{2}$ nanocrystalline thin films with a thickness of approximately $10 \mu \mathrm{m}$. RF-PECVD DLC thin films were introduced as an ARC on the upper working electrode. The working electrodes were dipped in $0.3 \mathrm{mM}$ ruthenium-complexed dye (Solarnix SA, Aubonne, Switzerland, N719, cis-Bis(isothiocyanato)bis(2,2'-bipyridyl-4,4'dicarboxylato)ruthenium(II)) as sensitizers for $24 \mathrm{~h}$ at room temperature. They were cleaned with ethanol and then dried with $\mathrm{N}_{2}$ gas. Counter electrode was fabricated by dropping $50-\mu \mathrm{LtCl}_{4}$ mixed with chloroplatinic acid (Sigma-Alldrich Inc., St. Louis, MO, USA) of $10 \mathrm{mM}$ and isopropyl alcohol on the FTO/glass and then sintered for $20 \mathrm{~min}$ at $450{ }^{\circ} \mathrm{C}$ in a furnace. The dye-adsorbed $\mathrm{TiO}_{2}$ working electrodes were bonded with the counter electrodes using a $60 \mu \mathrm{m}$ hot-melt Surlin spacer (Solaronix SA, Aubonne, Switzerland, SX 1170) at $100^{\circ} \mathrm{C}$ using a hot plate. Iodolyte (Solaronix SA, Aubonne, Switzerland, AN-50), as a low-viscosity electrolyte with tri-iodide of $50 \mathrm{mM}$ in acetonitrile, was injected into one of the two holes drilled into the counter electrodes, and the holes were then sealed with a cover glass and Surlin. The performance and the current-voltage characteristics of the DSSCs with different thicknesses of DLC ARC were implemented by a solar simulator (Abet Technologies Inc., Milford, CT, USA, Xe Lamps of 30 W, AM1.5).

\section{Results and Discussion}

The surface of the DLC thin films was evaluated to identify their tribological properties. The FESEM images of the RF-PECVD DLC thin films showed uniform and smooth surfaces in all specimens; the only significant difference was that the number of small grains tended to slightly increase as thickness increased, from which can be inferred that the density in the 
DLC thin films increased with growth. Figure 1 shows the root mean square (rms) surface roughness of the DLC thin films with a change in thicknesses. The three-dimensional (3D) AFM images identified a smooth and uniform surface similar to the FESEM images $[3,4]$. The rms surface roughness increased from 0.70 to $0.94 \mathrm{~nm}$ with an increase in thickness, which is believed to have been contributed by the increase in the number of small grains in the surfaces due to the increased kinetic energy of carbon and hydrogen ions in the plasma $[17,18]$, increased bonding for thin-film growth, and increased ion collisions near the surface $[19,20]$ with an increase in the deposition time for increasing the thickness of the DLC thin films with the fixed RF power.

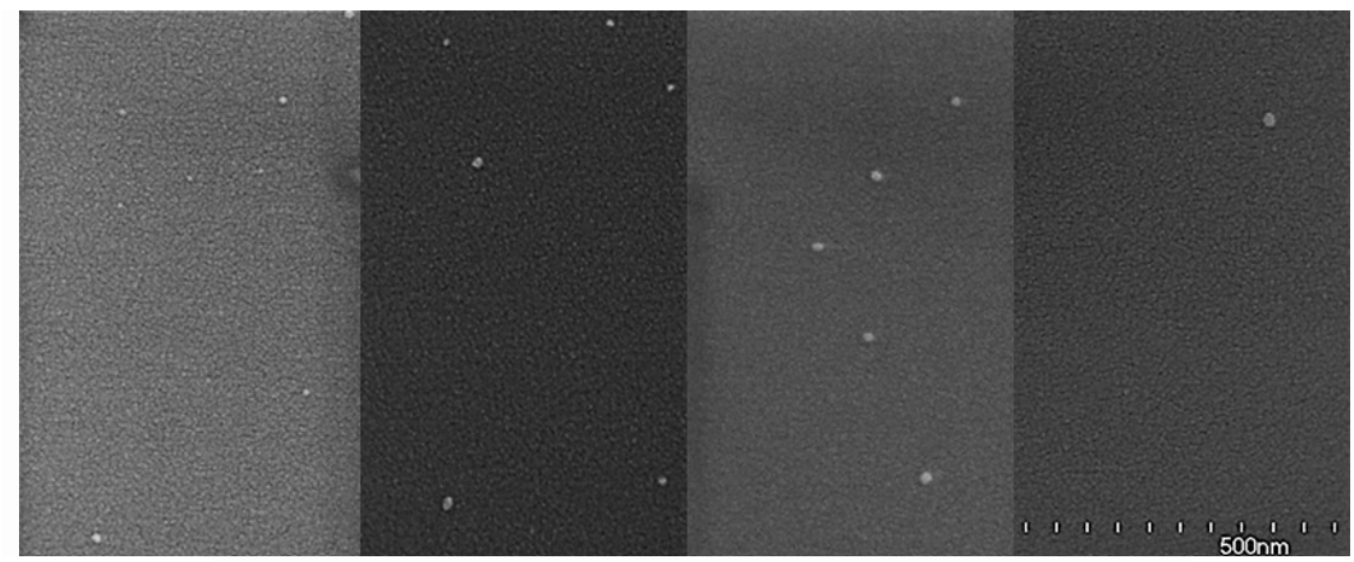

(a)

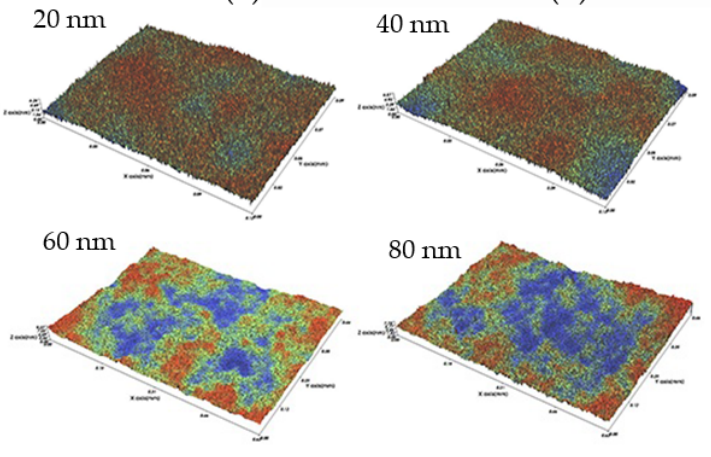

(e) (c)

(d)

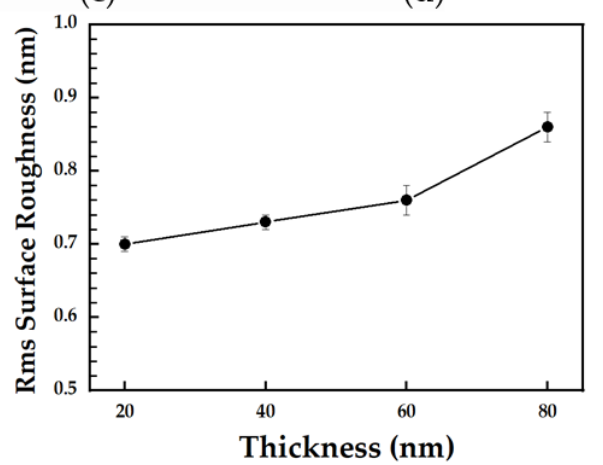

(f)

Figure 1. Field effect scanning electron microscope (FESEM) surface images of the radio frequency plasma-enhanced chemical vapor deposition (RF-PECVD) diamond-like carbon (DLC) thin films with various film thicknesses: (a) 20, (b) 40, (c) 60, and (d) $80 \mathrm{~nm}$. (e) Three-dimensional (3D) images and (f) rms surface roughness of the RF-PECVD DLC thin films for the same conditions obtained by atomic force microscopy (AFM).

Figure 2 shows the hardness, elastic modulus, and friction coefficient with changes in the thickness of the RF-PECVD DLC thin films. As the thickness of the DLC thin films increased, the hardness and elastic modulus increased, and the maximum values of the hardness and elastic modulus were approximately 14 and $210 \mathrm{GPa}$, respectively, at thickness of $100 \mathrm{~nm}$. These results indicate that the increased hardness and elastic modulus of the DLC thin films make the thin films denser with increasing thickness, and the ratio of diamond-like $\left(s p^{3}\right)$ content to amorphous bonding $\left(s p^{2}\right)$ in the DLC thin films increases [21,22]. Increasing the deposition time to increase the thickness of the thin film improves the bonding ratio of carbon and hydrogen, and the increased collisions of ions in the plasma near the surface increase the density of the DLC thin films and contribute to the increase in hardness and elastic modulus [6,7]. The friction coefficient of the DLC thin films showed a tendency to decrease from 0.017 to 0.013 with an increase in thickness. Although the slightly rougher surface in the thicker thin films, as shown in the FESEM and AFM results (Figure 1), had some effect on the increase in the friction coefficient [23], the 
increased film density of the DLC thin film as the thickness increased reduced the friction coefficient [24], which was affected by the modification in the ratio of $s p^{3}$ representing the binding of carbon and hydrogen in the thin films $[6,7]$.

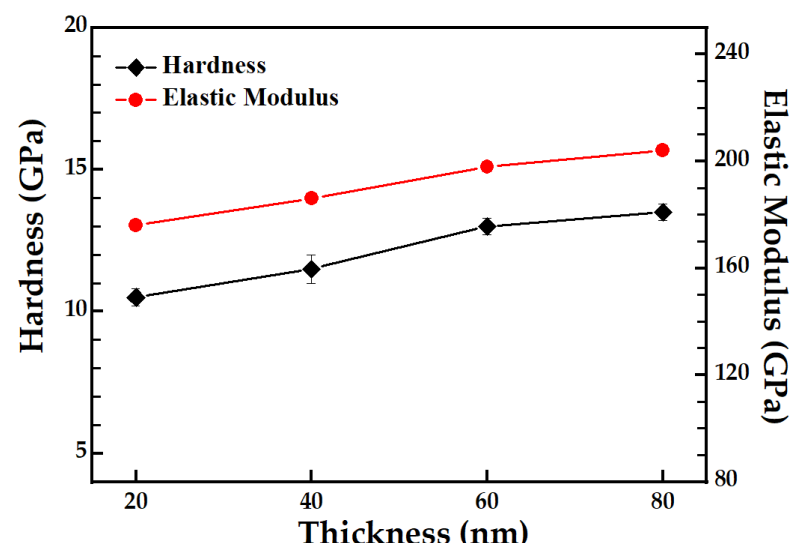

(a)

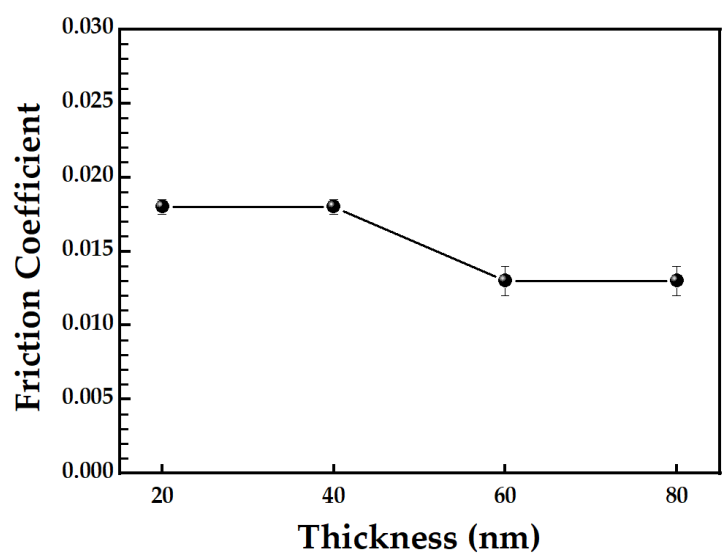

(b)

Figure 2. (a) Hardness and elastic modulus, and (b) friction coefficient in the RF-PECVD DLC thin films with various film thicknesses: 20, 40,60, and $80 \mathrm{~nm}$.

Figure 3 shows the contact angle of the DLC thin films with a change in thickness. The value of the contact angle on the surface exhibits a decreasing tendency from $86^{\circ}$ to $84^{\circ}$, but it was within the scope of a small change at varying DLC thin films thicknesses. The slight decrease in contact angle might be caused by the increase in the ratio of $s p^{3}$ showing hydrophilic properties on the surface. Generally, the surface shows the hydrophilic/hydrophobic properties according to the ratio of $s p^{3} / s p^{2}$ in the thin films [25]. The DLC thin films with higher $s p^{3}$ bonding fraction had a more hydrophobic surface than those with a higher $s p^{2}$ bonding fraction because the surface energy of the $s p^{3}$-terminated surface is very high due to its strong covalent character [26]. Owing to the hydrophobic properties of the DLC thin films, they are used as surface protectable and self-cleanable thin films. All DLC thin films in this study exhibited high contact angle values, which is highly likely to be applied to a functional coating for surface protection and self-cleaning.

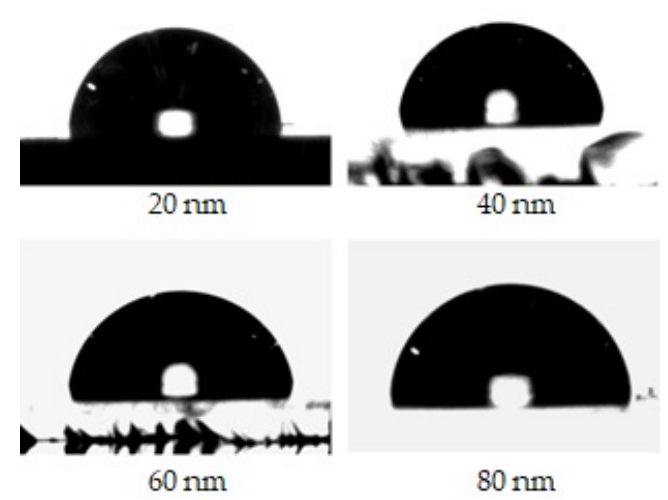

(a)

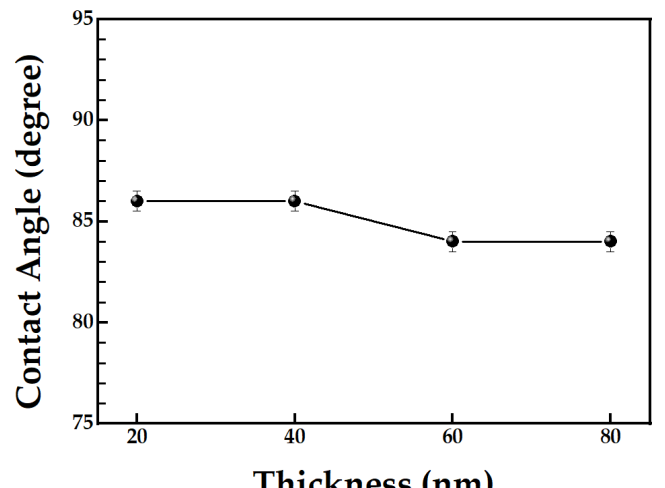

Thickness (nm)

(b)

Figure 3. Contact angle (a) images and (b) values of the RF-PECVD DLC thin films with various film thicknesses: 20, 40, 60, and $80 \mathrm{~nm}$.

The results of the Raman spectrum are presented in Figure 4, including the G-peak position and the ratio of the integrated areas under the D- and G-peaks $\left(I_{D} / I_{G}\right)$ in the RF-PECVD DLC thin films as measured with a change in thickness. The Raman spectrum shows the typical spectrum of the DLC thin films with an almost symmetrical carbon peak 
at approximately $1560 \mathrm{~cm}^{-1}$ and a silicon substrate peak at approximately $950 \mathrm{~cm}^{-1}$, with a weak shoulder at approximately $1370 \mathrm{~cm}^{-1}$ related to the disorder. The strength of the Raman peak increased slightly with an increase in the thickness of the DLC thin films, and Gaussian curve fitting for the Raman spectrum resulted in D (disordered) and G (graphitic) bands near 1370 and $1560 \mathrm{~cm}^{-1}$, respectively. As shown by the results of Gaussian curve fitting for the Raman spectrum (Figure S1), the G-peak shifted from 1558 to $1564 \mathrm{~cm}^{-1}$, and the $\mathrm{I}_{D} / \mathrm{I}_{G}$ ratio decreased from 0.290 to 0.148 , with an increase in thickness. The shift of the G-peak toward a relatively higher wavenumber and decrease in the $\mathrm{I}_{D} / \mathrm{I}_{G}$ ratio indicates a decrease in the $s p^{3}$ bonds in the DLC thin films, which is related to the density of the DLC thin film caused by the collision effect of carbon and hydrogen ions on the substrate surface with an increase in deposition time, a decrease in carbon $s p^{3}$ bonds due to a decrease in hydrogen ions, and an increase in the surface temperature of the thin-film surface $[6,7]$. In other words, the increase in deposition time brought the $s p^{3}$ bonding fraction in the DLC thin films to further reduce content of hydrogen as the surface temperature increases due to active binding on the thin-film surface and activation of the increased ions [6-8]. Beeman et al. reported that the disorder in the thin film increases as the energy of carbon ions exposed to plasma increases, and the hydrogen content in the thin film decreases the number of $s p^{3}$ bonds with hydrogen in the thin film; these affected the tribological and optical properties of the DLC thin films with increases in both intensity and full width at half maximum (FWHM) of the G-peak in the Raman analysis.

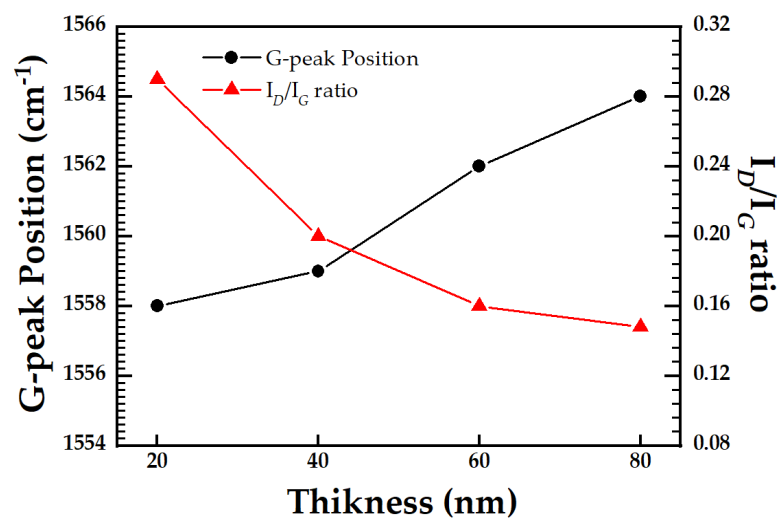

(a)

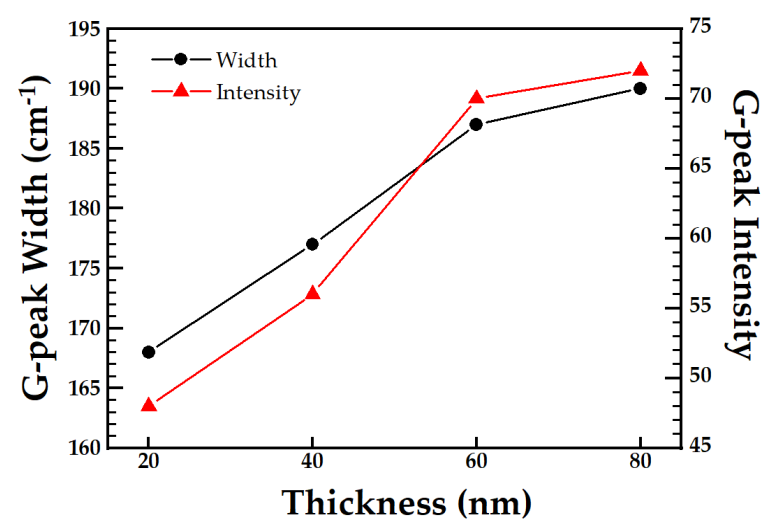

(b)

Figure 4. (a) G-peak position and $\mathrm{I}_{D} / \mathrm{I}_{G}$ ratio, and (b) G-peak width and intensity in the RF-PECVD DLC thin films with various film thicknesses: 20, 40, 60, and $80 \mathrm{~nm}$.

Figure 5 shows the optical properties, such as transmittance, reflectance, refractive index, and absorption coefficient, measured with an increase in the thickness of the RFPECVD DLC thin films. The transmittance of the DLC thin films tended to decrease as the thickness increased, and the transmittance of the $550 \mathrm{~nm}$ visible light decreased from $69 \%$ to $58 \%$. The refractive index and absorption coefficient of the DLC thin films increased from 1.400 to $2.124(633 \mathrm{~nm})$ and from 0.010 to 0.014 , respectively, with an increase in thickness. If DLC thin films can be regarded as a homogeneous medium, the absorption coefficient $\alpha(\lambda)$ and the absorbance $A_{a b s}$ were described by Beer-Lambert law and estimated by using Formulas (2) and (3):

$$
\begin{gathered}
A(\lambda)=I(\lambda)-R(\lambda)-T(\lambda), \\
A_{a b s}=-\ln \frac{T(\lambda)}{I(\lambda)-R(\lambda)}, \\
\alpha(\lambda)=\frac{A_{a b s}}{d}=d^{-1} \ln \frac{I(\lambda)-R(\lambda)}{T(\lambda)},
\end{gathered}
$$

where $d$ is the film thickness, $A(\lambda)$ is the intensity of light absorbed by the film, $I(\lambda)$ is the intensity of incident light to the film, $R(\lambda)$ is the intensity of reflected light on the 
surface, and $T(\lambda)$ is the intensity of illumination that passes through the film at a certain wavelength of $\lambda$. The increase in the thickness of the DLC thin films resulted in increased absorbance, which resulted from the decrease in the transmittance and/or reflectance. It can be concluded that there is a negligible effect of light scattering from the surface because the rms surface roughness was lower than $0.94 \mathrm{~nm}$ for all film thicknesses (Figure 1) [27]; therefore, the transmittance will be diminished if the reflectance of the thin films increases with increasing thickness [27]. The transmittance decreased because of the change in the thin-film microstructure due to the decrease in the $s p^{3}$ bonding fraction $[28,29]$ owing to the increase in the ratio of hydrogen bonds [26], while these results are also associated with an increase in $s p^{2}$ sites or clusters [26], as shown by the Gaussian curve fitting for the Raman spectrum [8-11]. The increased refractive index was caused by the increase in $s p^{2}$ sites or clusters, which resulted from the reduced bound hydrogen content and structurally densified thin films as the thickness of the DLC thin films increased [28].

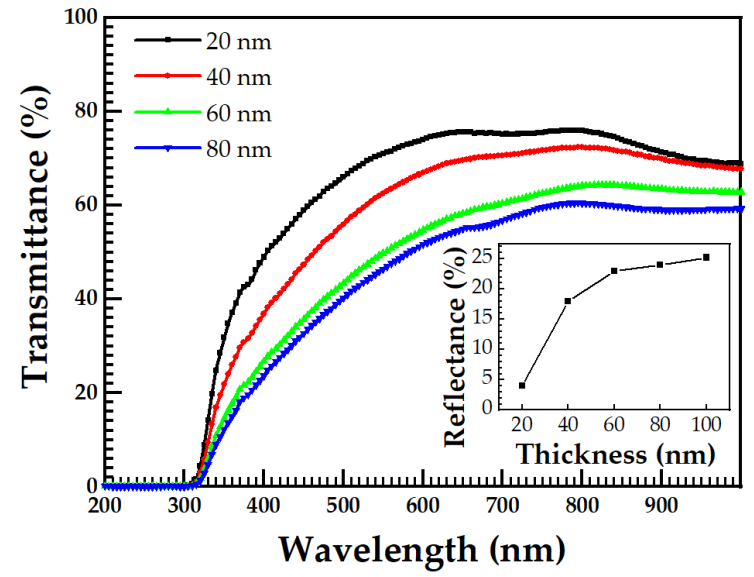

(a)

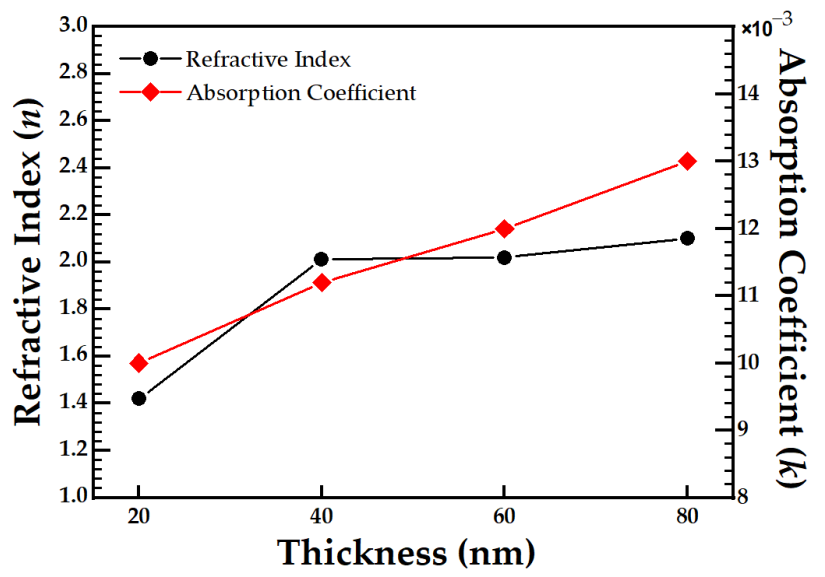

(b)

Figure 5. (a) Transmittance, (b) refractive index (n), and absorption coefficient $(k)$ of the RF-PECVD DLC thin films with various film thicknesses: 20,40,60, and $80 \mathrm{~nm}$. The inset of (a) shows reflectance of the RF-PECVD DLC thin films under the same film thicknesses.

Figure 6 shows the I-V curve showing the characteristics of DSSCs with the DLC ARC as a function of thickness, and the electrical characteristics of DSSCs with the DLC ARC are summarized in Table 1 . The open-circuit voltage $\left(V_{o c}\right)$ is determined by the difference between the Fermi level of the $\mathrm{TiO}_{2}$ working electrode and the oxidation/reduction level of the electrolyte. The fill factor (FF) is generally due to the internal DSSC resistances, such as FTO sheet resistance, resistance to charge movement in working/counter electrodes, and diffusion resistance of ion species in the electrolyte. The short-circuit current density $\left(J_{s c}\right)$ of DSSCs could be controlled at a similar level from 11.93 without the DLC ARC to 12.11 and to $11.38 \mathrm{~mA} / \mathrm{cm}^{2}$ with the DLC ARC. For DSSCs, the increase in $J_{s c}$ is associated with an increase in incident photons; an improved $J_{s c}$ of $12.11 \mathrm{~mA} / \mathrm{cm}^{2}$ was obtained at a thickness of $20 \mathrm{~nm}$ with an increase in the incident photons through reflection protection, while a diminished $J_{s c}$ of $9.79 \mathrm{~mA} / \mathrm{cm}^{2}$ was observed for a thickness of $80 \mathrm{~nm}$ with a sharp decrease in the transmittance from the thicker ARC. The increase in $V_{o c}$ of the DSSCs results from a passivation effect of DLC thin films that suppresses the recombination current [30]. The measured $V_{o c}$ and FF values show differences with changes in the thickness of the DLC ARC. Thus, a significant improvement in the CE was obtained from $4.92 \%$ to $5.35 \%$ when applying the DLC ARC owing to the amount of photons in the DSSCs with the proper thickness of ARC. In particular, the DSSCs with the DLC ARC of $60 \mathrm{~nm}$ showed an improvement of $8.73 \%$ in CE compared with the established DSSCs without ARC. 


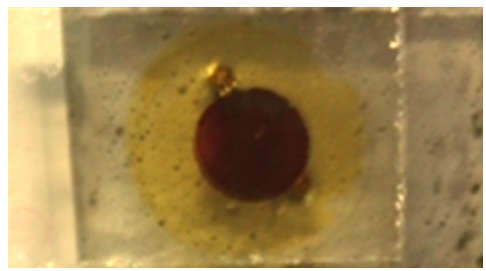

(a)

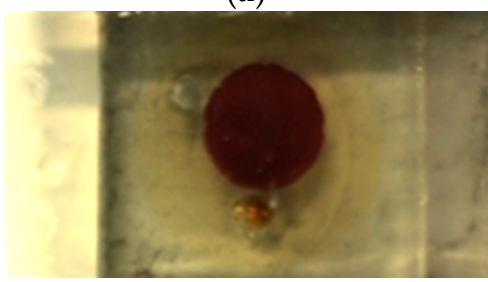

(b)

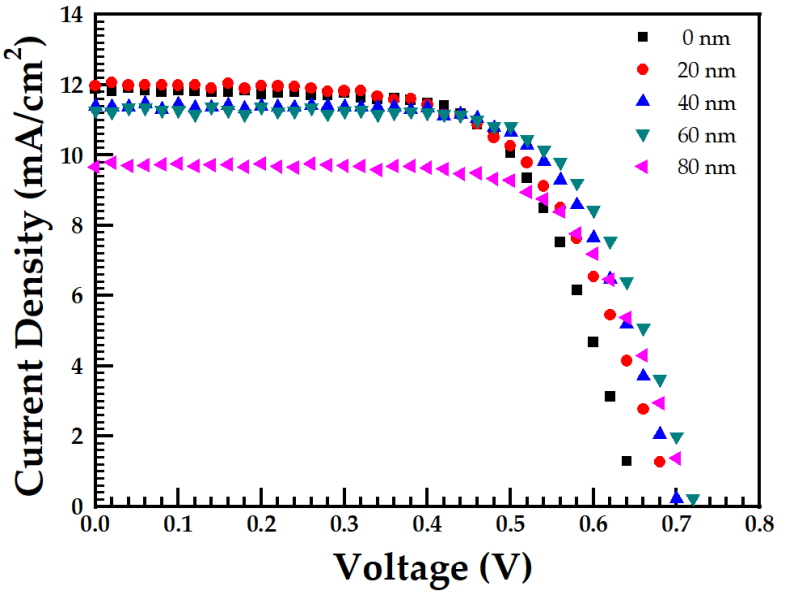

(c)

Figure 6. Dye-sensitized solar cells (DSSCs) (a) without and (b) with the RF-PECVD DLC antireflective coatings (ARCs). (c) Cell characteristics ( $J-V$ curves) of the DSSCs with different thickness of the RF-PECVD DLC ARC compared with the non-ARC cell.

Table 1. Optoelectronic properties of the DSSCs with different thickness of the RF-PECVD DLC ARC compared with the non-ARC cell.

\begin{tabular}{ccccc}
\hline Thickness (nm) & CE (\%) & $V_{\boldsymbol{o c}} \mathbf{( V )}$ & $J_{\boldsymbol{s c}}\left(\mathbf{m A} \mathbf{\mathbf { c m } ^ { 2 }}\right)$ & FF (\%) \\
\hline 0 & 4.92 & 0.649 & 11.93 & 63.58 \\
20 & 5.00 & 0.691 & 12.11 & 59.70 \\
40 & 5.21 & 0.698 & 11.50 & 65.35 \\
60 & 5.35 & 0.719 & 11.38 & 64.99 \\
80 & 4.60 & 0.713 & 9.79 & 65.97 \\
\hline
\end{tabular}

\section{Conclusions}

The RF-PECVD system was used to manufacture DLC thin films. The tribological, optical, and structural properties of the DLC thin films were analyzed at varying thicknesses, and the correlation between the properties was considered for the application of DLC thin films to the ARC of DSSCs. As the thickness of the DLC thin films increased, the surface roughness and friction coefficient slightly increased, the hardness and elastic modulus increased, and the contact angle decreased somewhat. The transmittance of visible light at $550 \mathrm{~nm}$ decreased, while the refractive index and absorption coefficient increased with an increase in thickness. The strength of the Raman spectrum increased slightly; the G-peak shifted toward a relatively higher wavenumber as a result of Gaussian curve fitting for the Raman spectrum; and the $\mathrm{I}_{D} / \mathrm{I}_{G}$ ratio decreased, which means that the $s p^{3}$ bonds in the DLC thin films decreased, and the collision between carbon and hydrogen ions in the plasma increased on the surface as the deposition time increased, the carbon $s p^{3}$ bonds decreased due to the reduction in hydrogen ions, and thus the DLC thin films became densified due to the increased surface temperature. The optimal $J_{s c}, V_{o c}$, and FF values with a change in the thickness of the DLC thin films were chosen for the significantly improved CE from $4.92 \%$ to $5.35 \%$ in the 60 -nm-thick DLC ARC for DSSCs, with a hard and hydrophobic surface for protective and self-cleaning surfaces.

Supplementary Materials: The following is available online at https:/ / www.mdpi.com/2076-3417/ 11/1/358/s1, Figure S1: Gaussian fitting of Raman spectra for the RF-PECVD DLC thin films with various film thicknesses: (a) 20, (b) 40, (c) 60, and (d) $80 \mathrm{~nm}$. 
Author Contributions: Conceptualization, Y.S.P. and N.-H.K.; investigation, J.-S.S.; data curation, Y.S.P.; writing-original draft preparation, J.-S.S. and Y.S.P.; writing—review and editing, N.-H.K.; project administration, N.-H.K.; funding acquisition, N.-H.K. All authors have read and agreed to the published version of the manuscript.

Funding: This work was supported by the Korea Institute of Energy Technology Evaluation and Planning (KETEP) and the Ministry of Trade, Industry and Energy(MOTIE) of the Republic of Korea (No. 20184010201650). This study was supported by a research fund from Chosun University, 2017.

Informed Consent Statement: Not applicable.

Data Availability Statement: Data is contained within the article or supplementary material.

Conflicts of Interest: The authors declare no conflict of interest. The founding sponsors had no role in the design of the study; in the collection, analyses, or interpretation of data; in the writing of the manuscript, and in the decision to publish the results.

\section{References}

1. Fiaschi, G.; Rota, A.; Ballestrazzi, A.; Marchetto, D.; Vezzalini, E.; Valeri, S. A Chemical, Mechanical, and Tribological Analysis of DLC Coatings Deposited by Magnetron Sputtering. Lubricants 2019, 7, 38. [CrossRef]

2. Hatada, R.; Flege, S.; Ashraf, M.N.; Timmermann, A.; Schmid, C.; Ensinger, W. The Influence of Preparation Conditions on the Structural Properties and Hardness of Diamond-Like Carbon Films, Prepared by Plasma Source Ion Implantation. Coatings 2020, 10, 360. [CrossRef]

3. Voevodin, A.A.; Rebholz, C.; Schneider, J.M.; Stevenson, P.; Matthews, A. Wear resistant composite coatings deposited by electron enhanced closed field unbalanced magnetron sputtering. Surf. Coat. Technol. 1995, 73, 185-197. [CrossRef]

4. Monaghan, D.P.; Teer, D.G.; Logan, P.A.; Efeoglu, I.; Arnell, R.D. Deposition of wear resistant coatings based on diamond like carbon by unbalanced magnetron sputtering. Surf. Coat. Technol. 1993, 60, 525-530. [CrossRef]

5. Ander, A. Ion charge state distributions of vacuum arc plasmas: The origin of species. Phys. Rev. E 1997, 55, 969-981. [CrossRef]

6. Chuang, F.Y.; Wang, W.C.; Cheng, H.F.; Sun, C.Y.; Lin, I.N. Field emission characteristics of diamondlike carbon films synthesized by pulsed laser deposition process using a Au-intermediate layer. J. Vac. Sci. Technol. B 1997, 15, 2072-2076. [CrossRef]

7. Kwok, S.C.H.; Zhang, W.; Wan, G.J.; McKenzie, D.R.; Bilek, M.M.M.; Chu, P.K. Hemocompatibility and anti-bacterial properties of silver doped diamond-like carbon prepared by pulsed filtered cathodic vacuum arc deposition. Diam. Relat. Mater. 2007, 16, 1353-1360. [CrossRef]

8. Roy, R.K.; Choi, H.-W.; Park, S.-J.; Lee, K.-R. Surface energy of the plasma treated Si incorporated diamond-like carbon films. Diam. Relat. Mater. 2007, 16, 1732-1738. [CrossRef]

9. Litovchenko, V.G.; Klyui, N.I. Solar cells based on DLC film—Si structures for space application. Sol. Energy Mater. Sol. Cells 2001, 68, 55-70. [CrossRef]

10. Pern, F.J.; Panosyan, Z.; Gippius, A.A.; Kontsevoy, J.A.; Touryan, K.; Voskanyan, S.; Yengibaryan, Y. Diamond-Like Carbon Coatings as Encapsulants for Photovoltaic Solar Cells. In Proceedings of the Conference Record of the Thirty-First IEEE Photovoltaic Specialists Conference, Lake Buena Vista, FL, USA, 3-7 January 2005; IEEE Operations Center: Piscataway, NJ, USA, 2005; pp. 1339-1342. [CrossRef]

11. Klibanov, L.; Croitoru, N.; Seidman, A.; Scheffer, L.; Ben-Jacob, E. Influence of nitrogen doping on photoconductivity properties of a: DLC films. Diam. Relat. Mater. 1997, 6, 1868-1873. [CrossRef]

12. Park, N.-G.; Kim, K. Transparent solar cells based on dye-sensitized nanocrystalline semiconductors. Phys. Status Solidi A 2008, 205, 1895-1904. [CrossRef]

13. O'Regan, B.; Gratzel, M. A low-cost, high-efficiency solar cell based on dye-sensitized colloidal $\mathrm{TiO}_{2}$ films. Nature 1991, 353, 737-740. [CrossRef]

14. Hauert, R. A review of modified DLC coatings for biological applications. Diamond Relat. Mater. 2003, 12, 583-589. [CrossRef]

15. Tochitsky, E.I.; Beliavsky, N.M.; Sviridovich, O.G.; Lopatin, S.D.; Dudarchik, I.V. UV-Sensors from Diamond-Like Carbon Films. In Diamond and Diamond-Like Film Applications, 1st ed.; Gielisse, P.J., Ivanov-Omskii, V.I., Popovici, G., Prelas, M., Eds.; CRC Press: New York, NY, USA, 1998; pp. 46-50.

16. Oh, B.-Y.; Park, Y.S. Characteristics of Diamond-Like Carbon Films Fabricated by Using a Filtered Vacuum Arc System for Dye-Sensitized Solar Cells. J. Korean Phys. Soc. 2019, 75, 586-590. [CrossRef]

17. Ward, L.; Junge, F.; Lampka, A.; Dobbertin, M.; Mewes, C.; Wienecke, M. The Effect of Bias Voltage and Gas Pressure on the Structure, Adhesion and Wear Behavior of Diamond Like Carbon (DLC) Coatings with Si Interlayers. Coatings 2014, 4, 214-230. [CrossRef]

18. Zhou, K.; Ke, P.; Li, X.; Zou, Y.; Wang, A. Microstructure and electrochemical properties of nitrogen-doped DLC films deposited by PECVD technique. Appl. Surf. Sci. 2015, 329, 281-286. [CrossRef]

19. Dai, Z.; Yan, F.; Chen, J.; Ju, H. Reagentless Amperometric Immunosensors Based on Direct Electrochemistry of Horseradish Peroxidase for Determination of Carcinoma Antigen-125. Anal. Chem. 2003, 75, 5429-5434. [CrossRef] [PubMed]

20. Donnet, C. Advanced solid lubricant coatings for high vacuum environments. Surf. Coat. Technol. 1996, 80, 151-156. [CrossRef] 
21. Ito, H.; Yamamoto, K. Mechanical and tribological properties of DLC films for sliding parts. Kobelco Technol. Rev. 2017, 35, 55-60. Available online: https:/ / www.kobelco.co.jp/english/ktr/ktr_35.html (accessed on 1 December 2020).

22. Písařík, P.; Jelínek, M.; Kocourek, T.; Remsa, J.; Zemek, J.; Lukeš, J.; Šepitka, J. Influence of diamond and graphite bonds on mechanical properties of DLC thin films. J. Phys. Conf. Ser. 2015, 594, 012008. [CrossRef]

23. Erdemir, A.; Donnet, C. Tribology of Diamond, Diamond-Like Carbon, and Related Films. In Modern Tribology Handbook, 1st ed.; Bhushan, B., Ed.; CRC Press: New York, NY, USA, 2001; pp. 871-908. [CrossRef]

24. Yasui, H.; Taki, M.; Hasegawa, Y.; Takago, S. Mechanical properties of high-density diamond like carbon (HD-DLC) films prepared using filtered arc deposition. Surf. Coat. Technol. 2011, 206, 1003-1006. [CrossRef]

25. Duta, L.; Popescu, A.C.; Zgura, I.; Preda, N.; Mihailescu, I.N. Wettability of Nanostructured Surfaces. In Wetting and Wettability, 1st ed.; Aliofkhazraei, M., Ed.; IntechOpen Ltd.: London, UK, 2015; pp. 207-252. [CrossRef]

26. Paul, R.; Das, S.N.; Dalui, S.; Gayen, R.N.; Roy, R.K.; Bhar, R.; Pal, A.K. Synthesis of DLC films with different $s p^{2} / s p^{3}$ ratios and their hydrophobic behaviour. J. Phys. D Appl. Phys. 2008, 41, 055309. [CrossRef]

27. Lin, C.-R.; Chang, H.-M.; Chang, C.-K. Fabrication of High Transparency Diamond-Like Carbon Film Coating on D263T Glass at Room Temperature as an Antireflection Layer. Int. J. Photoenergy 2013, 2013, 612163. [CrossRef]

28. Adlienė, D.; Laurikaitienė, J.; Kopustinskas, V.; Meškinis, Š.; Šablinskas, V. Radiation induced changes in amorphous hydrogenated DLC films. Mater. Sci. Eng. B 2008, 152, 91-95. [CrossRef]

29. Ding, X.-L.; Li, Q.-S.; Kong, X.-H. Optical and Electrical Properties Evolution of Diamond-Like Carbon Thin Films with Deposition Temperature. Chin. Phys. Lett. 2009, 26, 027802. [CrossRef]

30. Aurang, P.; Demircioglu, O.; Es, F.; Turan, R.; Unalan, H.E. ZnO Nanorods as Antireflective Coatings for Industrial-Scale Single-Crystalline Silicon Solar Cells. J. Am. Ceram. Soc. 2013, 96, 1253-1257. [CrossRef] 